\title{
Peer Support, Self-efficacy, and Combat-related Trauma Symptoms among Returning OIF/OEF Veterans
}

\author{
Ann MacEachron \\ Nora Gustavsson
}

\begin{abstract}
The incidence of PTSD and other combat-related trauma symptoms among more than 2 million veterans returning from Operation Iraqi Freedom (OIF) and Operation Enduring Freedom (OEF) in Afghanistan suggests that many will experience psychological challenges in adjusting to civilian life. However, the literature is sparse about this new group of veterans. This study examined the relationships between peer support, self-efficacy, and PTSD symptoms among 216 OIF/OEF veterans who had attended 1 of 17 Vets4Vets peer support weekend retreats. Vets4Vets is a national grassroots program whose mission is to improve the psychological well-being of returning OIF/OEF veterans. Analysis of posttest changes indicate the generalizability of previous research findings, based on other groups of trauma-affected groups, to OIF/OEF veterans. As predicted, increased perceived peer support and self-efficacy reduced PTSD symptoms. From a theoretical perspective, we found that both models of self-efficacy, situation-specific (Bandura, 1997; Benight \& Bandura, 2004) and general self-efficacy (Schwarzer \& Fuchs, 1996), mediated or explained the relationship between peer support and PTSD symptoms. Implications for social work are discussed.
\end{abstract}

Keywords: Veterans, peer support, PTSD, social support, self-help, self-efficacy, general self-efficacy

\section{INTRODUCTION}

After more than a decade of war in Iraq (OIF, Operation Iraqi Freedom) and Afghanistan (OEF, Operation Enduring Freedom) and with more than 2.6 million troops deployed, a continuing challenge is taking care of veterans who have endured these wars. While it is known that veterans may experience multiple physical challenges, recognition is growing in regards to the psychological and social consequences of deployment, extended or multiple tours of duty, and combat (Burnam, Tanielian, \& Jaycox, 2009; Eibner, 2008; Institute of Medicine, 2010). Reviews of the literature (Schell \& Tanielian, 2011; Tanielian \& Jaycox 2008) indicate that the prevalence of posttraumatic stress disorder (PTSD) ranges from about 5 to 15 percent for returning OIF/OEF veterans. Recurrent PTSD symptoms often interfere with, if not impair, functioning in personal, social, and work realms. Another recently publicized risk is the increasing prevalence of suicide among both soldiers and veterans. The Center for New American Security (2011) recently estimated that a veteran dies from suicide about every 80 minutes.

Peer support is increasingly recognized as an important component of mental health services for improving psychological well-being among veterans. Peer support is viewed as being congruent with veterans' common experience of military culture where a high value is placed on camaraderie and unit cohesion (Barber, Rosenheck, Armstrong, \&

Ann MacEachron, Ph.D., is a Professor and Nora Gustavsson, Ph.D., is an Associate Professor, both at the College of Public Programs, School of Social Work, Arizona State University in Phoenix.

Copyright (C) 2012 Advances in Social Work Vol. 13 No. 3 (Fall 2012), 586-602 
Resnick, 2008; Center for New American Security, 2011; Poole, 2010; Schell \& Tanielian, 2011; Seligman, 2011; Tanielian \& Jaycox, 2008). From a social cognitive perspective of self-efficacy theory, the effectiveness of peer support may be explained in terms of an individual's improved self-efficacy due to peer learning about how to cope with and manage a stressful environment (Bandura, 1997; Benight \& Bandura, 2004). The focus of our study is evaluating a national, grassroots peer support veterans program, called Vets4Vets. Founded in 2004, Vets4Vets is among the 50 outstanding nonprofits to receive an award through the 2006 Iraq-Afghanistan Deployment Impact Fund (NBC Nightly News Weekend Edition, 2009). The award was for using intensive peer support weekend retreats to help veterans "heal from the psychological injuries of war" (Vets4Vets, 2011). In this pretest-posttest study OIF/OEF veterans who participated in the weekend peer support program, the first research question focuses on the potential generalizability of previous research findings among trauma-affected groups to OIF/OEF veterans: Do PTSD symptoms of OIF/OEF veterans lessen with increased peer support and self-efficacy? From a conceptual perspective, the second research question examines self-efficacy as a mediating explanatory variable: Does self-efficacy explain the predicted relationship between peer support and PTSD symptoms.

\section{Peer Support}

Kurtz (1997) defined a self-help group as "a supportive, educational, usually changeoriented mutual-aid group that addresses a single life problem or condition shared by all members" (p. 4). The condition shared among peer support groups is often a traumatic experience. Mead, Hilton, and Curtis (2001) define peer support as "a system of giving and receiving help founded on key principles of respect, shared responsibility, and mutual agreement of what is helpful...It is about understanding another's situation emphatically through the shared experience of emotional and psychological pain” (p. 135). Brown and Lucksted (2010) suggest that there are multiple, overlapping dimensions to peer support. It is not just a common experience but also a healing and empowering process.

The experiential principle is key to peer support because it creates a relationship based on a shared life experience to foster understanding, trustworthiness, and safety in helping relationships (Hegelson \& Gottlieb, 2000; Mead et al., 2001; Solomon, 2004). The peer group process offers the opportunity to learn from the coping competency of others. Peers not only model and demonstrate coping and adaptive skills but also offer contextual wisdom through personal stories of recovery or adaptive coping (Solomon, 2004).

Overall, peer support is a well-established pathway to reduce vulnerability to stress and depression by emphasizing strengths and coping resilience to overcome trauma and rebuild one's life (Bandura, 1997; Calhoun \& Tedeschi, 2006; Saleebey, 2006; Schwarzer, 1992; Seligman, 2011). A meta-analysis by Brewin, Andrews, and Valentine (2000) showed a strong relationship between greater peer support and reduced PTSD symptoms among high-risk populations. A later meta-analysis of PTSD predictors by Ozer, Best, Lipsey, and Weiss (2003) found that this inverse relationship was strongest in studies of combat trauma among American veterans of the Vietnam War and the Persian Gulf War. More recently, a cross-sectional mail survey of OIF/OEF veterans (Pietrzak, 
Goldstein, Malley, Rivers, \& Southwick, 2010) reported that reduced social support was related to increased PTSD symptom severity. The Pietrzak et al. study is the only study to investigate and demonstrate this inverse hypothesis for OIF/OEF veterans. We also examine this inverse hypothesis among OIF/OEF veterans but from a change perspective. It is expected that participants who experienced increased peer support from the Vets4Vets weekend peer support program will report reduced perceived PTSD symptoms.

\section{Self-efficacy}

From a conceptual perspective of social cognition, peer support is effective because peers together demonstrate and learn how to be self-efficacious in coping. Peers "model coping attitudes and skills, provide incentives for engagement in beneficial activities, and motivate others by showing that difficulties are surmountable by perseverant effort" (Benight \& Bandura, 2004, p. 1134). However, self-efficacy has been conceptualized in two distinct ways by Bandura (1997) and by Schwarzer and Jerusalem (1995).

From Bandura's perspective, perceived self-efficacy in coping is the "core belief that one has the power to produce desired effects by one's actions" and "plays a key role in stress reactions and quality of coping in threatening situations" (Benight \& Bandura, 2004, p. 1131). Self-efficacy reduces the effect of a stressor by enabling individuals to use proactive coping strategies. Individuals with high self-efficacy see challenges as mastery tasks, focus on strengths, and recover more quickly from setbacks. Individuals with low self-efficacy see challenges as areas of personal failure, focus on their failings, and have low confidence in themselves. Self-efficacy is thus a key component of resilience to trauma (Bandura, 1994). Combat traumatization, as discussed by Benight and Bandura (2004), has received very limited attention in the research literature. Among the very few available studies, Benight and Bandura found that low perceived selfefficacy among Israeli soldiers was related to more trauma symptoms experienced. Our second hypothesis is that increased situation-specific self-efficacy reduces perceived PTSD symptoms among OIF/OEF veterans.

Self-efficacy as defined by Bandura (1997) is situation-specific, that is, depends on the particular context and activity. It focuses on an adaptive functioning relative to the surrounding circumstances, context, and goals. An alternative conceptualization is that of an omnibus or general self-efficacy. General self-efficacy is an optimistic "self-belief that one can perform ... difficult tasks or cope with adversity - in various domains of human functioning" (Schwarzer \& Jerusalem, 1995, p. 1). It is a stable adaptive strategy if not trait based on an optimism regarding one's coping ability (Schwarzer, 1992). Vernon, Dillon, and Steiner (2009), found general self-efficacy to be one of several proactive coping factors in reducing PTSD symptoms among undergraduate women with trauma backgrounds. This conceptualization suggests that people higher in general self-efficacy are more likely to have less intense trauma symptoms, set higher goals, persist towards their goals despite obstacles, and create opportunities for personal growth. However, there is no available literature in this regard in terms of combat traumatization. Our third hypothesis is that increased general self-efficacy reduces perceived PTSD symptoms among OIF/OEF veterans. 
From a social cognitive perspective, individuals are proactive both in adapting to the multi-causality inherent to environmental challenges and risks and in developing competencies and regulating their actions (Bandura, 1997). Resilience to adversity is viewed as relying "more on personal enablement than on environmental protectiveness" or on proactivity rather than reactivity (Benight \& Bandura, 2004, p. 1133). To the extent that peer support enables learning of adaptive knowledge and coping skills within a multi-causal context, it fosters what Bandura calls self-efficacy. Peer supporters provide a social learning context in which they model a variety of coping skills across multiple situations as well as encourage perseverance in achieving mastery over trauma-related symptoms or other goals. The explanatory link between support and reduced traumarelated symptoms is self-efficacy. Self-efficacy requires a proactive approach to find, maintain, and learn from peers. Benight and Bandura's 2004 review of the literature discussed the important mediating role played by self-efficacy: "social support produces beneficial outcomes only to the extent that it raises perceived self-efficacy to manage environmental demands” (p. 1134).

As Benight and Bandura noted, much more research is needed to evaluate selfefficacy as a mediator especially in regards to explaining the relationship between social support and combat-related trauma. Our fourth hypothesis is that Bandura's situationspecific self-efficacy will play a mediator role in explaining the relationship between peer support and perceived PTSD symptoms at posttest. Interestingly, no study has yet compared the explanatory power of situation-specific self-efficacy and general selfefficacy in terms of peer support and such trauma outcomes as combat traumatization. While Schwarzer and Fuchs (1996) do not highlight the distinction, Bandura (1997) believed that situation-specific self-efficacy would be a stronger predictor and mediator variable than would general self-efficacy. Our fifth hypothesis is that Schwarzer's concept of general self-efficacy will also play a mediator role in explaining the relationship between peer support and perceived PTSD symptoms at posttest.

\section{Vets4Vets Program}

Since World War II, peer support and peer services have grown exponentially (Brown \& Lucksted, 2010; Campbell, 2005; Clay, 2005; Davidson et al., 1999). This growth is especially evident in the mental health and addictions field with many Anonymous programs for alcohol, drugs, gambling, and other issues (Solomon, 2004). Since the 1970s, peer support has been a component of the Community Support System in mental health as well as other mental health services (Goldstrom et al., 2006; Solomon, 2004). Peer support in mental health services is also expanding in the Veteran's Administration (Barber et al., 2008; Resnick \& Rosenheck, 2008). There is substantial variation in the purpose, format, and setting for peer support, for example, one-on-one sessions, small to larger groups, face-to-face versus online, therapeutic or personal growth, and short-term intensive retreats versus ongoing sessions (Hirschhorn \& Gilmore, 2004; Liteman, Cambell, \& Liteman, 2006; Martone, 2010; Orloff, Armstrong, \& Remke, 2009; Rains \& Young, 2009).

Vets4Vets is a national grassroots organization that works with OIF/OEF veterans to develop local peer support groups and to coordinate these groups to become a national 
network. One part of their peer support program is to hold regional intensive weekend retreats. The residential retreats start on Friday afternoon and end on Sunday noon. The leaders are also OIF/OEF veterans and ongoing members of local Vets4Vets peer support groups. They receive 40 hours of classroom training, co-facilitate several retreats before leading a retreat, and follow a manualized script for the scheduling and content of each retreat hour. Each retreat emphasizes peer support through engagement in multiple group sessions throughout the weekend. The groups encourage members to talk openly about and re-evaluate their military experiences, to use active listening skills, to re-experience camaraderie or social connectedness of peers, discuss challenges to reentry to civilian life, and recognize common issues for advocacy within their veteran communities.

\section{METHODS}

\section{Sample}

A total of 325 of 466 OIF/OEF (70\%) veterans completed either a pretest or posttest while attending one of 17 Vets4Vets weekend retreats between January 2010 and January 2011. Most groups were led by the same leader but 5 of the 17 groups had two different leaders. However, there were no significant mean differences between groups in terms of perceived peer support or PTSD symptoms at the pretest or posttest as assessed by oneway analyses of variance.

Given veteran reluctance to share information about combat-related trauma (e.g., Schell \& Tanielian, 2011), anonymous identifiers were chosen by participants to selfidentify each test. Using these identifiers, a total of 216 participants (46\% response rate) completed both the pretest and posttest.

To maintain the anonymity of participants, the only background information collected was for age, gender, and race/ethnicity. Participants were 37 years old on average (sd $=11$ ). About $40 \%$ of participants were married and $60 \%$ were single. The majority were males (70\%). Most participants were white (58\%), and then Hispanic American (14\%), African American (13\%), Native American (3\%), Asian American (less than $1 \%)$, or others who did not report their race or ethnicity $(9 \%)$. There was no significant difference on background characteristics for participants who either completed both tests or just one test.

\section{Research Design}

Vets4Vets followed a pretest-posttest, one group design (Rubin \& Babbie, 2010). A pretest was given to participants during the first evening (Friday) of the weekend retreat and a posttest the following Sunday at the end of the retreat. Vets4Vets staff designed the survey and collected the pretest-posttest data, but the authors coded the data. The university IRB reviewed and approved use of this secondary data for this study.

\section{Measures}

Peer support. A key theme of peer support is the feeling of social connectedness, a theme that we measured in this study by the Social Connectedness Scale (SC). SC is 
based on Kohut's (1984) concept of belongingness or closeness with others in contrast to social isolation or "emotional distance between self and others" (Lee \& Robbins, 1995, p. 236). The SC scale is the average of 8 items such as, "I have little sense of togetherness with my peers." Each item is assessed by reverse scoring of a 6-point scale ranging from $1=$ "Strongly Agree" to $6=$ "Strongly Disagree." A higher score represents higher perceived social connectedness. Cronbach's alpha of reliability is .96 in the pretest and .95 in the posttest. These reliabilities are consistent with the high reliabilities of .91 reported in Lee and Robbins (1995) and .94 reported in Lee, Draper and Lee (2001).

General self-efficacy. The General Efficacy Scale (GSE) measures an individual's general sense of self-efficacy in coping with daily hassles and adapting to stress across domains of human functioning (Schwarzer \& Fuchs, 1996; Schwarzer \& Jerusalem, 1995). The GSE is the average of ten items such as "I can always manage to solve difficult problems if I try hard enough.” Each item is rated on a 4-point scale ranging from 1= "Not at all true" to $4=$ "Exactly true." A higher score represents a higher perceived general self-efficacy. Cronbach's alpha of reliability is .92 for both the pretest and posttest and is thus consistent with previously reported reliabilities in the high .80s (Schwarzer \& Fuchs, 1996; Schwarzer \& Jerusalem, 1995).

Situation-specific self-efficacy. The situation-specific self-efficacy (SE) measure is the average of four items developed by the Vets4Vets staff to tap coping with combatrelated trauma. An example is: "I feel confident that I can manage any PTSD and related symptoms, or any effects of military service - such as sometimes feeling bad or guilty about my military service, getting angry easily, feeling isolated." Each item is measured on a 6-point scale ranging from 1 = "Strongly disagree" to $6=$ "Strongly agree." A higher score represents higher perceived situation-specific self-efficacy. The Cronbach's alpha is .82 for the pretest and .84 for the posttest.

PTSD. Perceived PTSD is measured by the global screening instrument called SPRINT (Connor \& Davidson, 2001; Davidson \& Colket, 1997). SPRINT contains 8 items such as, "How much have you been bothered by unwanted memories, nightmares, or reminders of the event." Each item is measured on a 4-point scale ranging from $1=$ "Not at all" to 4 = "Quite a bit." A higher average score represents a higher perceived risk of experiencing PTSD symptoms. The SPRINT has been reported as responsive to change over time and has high diagnostic accuracy and internal consistency. In this study, the Cronbach's alpha of reliability is .93 for the pretest and .94 for the posttest.

Control variables. Previous research has found that age, gender, and marital status may influence perceived PTSD symptoms (e.g., Carter-Visscher, et al., 2010; Worthen, 2011), self-efficacy (e.g., Bandura, 1997), and/or social support from peers (e.g., Brown $\&$ Lucksted, 2010). Thus, our analyses control for gender ( $0=$ male, $1=$ female), age, and marital status $(0=$ not married, $1=$ married $)$.

The measurement of change requires adjusting posttest scores for pretest differences. Dimitrov and Rumrill (2003) recommend using ANCOVA with a pretest-posttest design that regresses each posttest on its pretest covariate. Thus, in addition to the control variables of gender, age and marital status, we entered pretests scores as covariates in 
regression analyses before evaluating posttest change for peer support, GSE, SE, and PTSD symptoms.

Statistical Analysis. PASW Statistics 20 was used for all statistical analyses. For descriptive purposes, Pearson correlations evaluated the strength and significance of bivariate relationships between all measures, while paired t-tests evaluated pretestposttest mean differences of each independent and dependent variable.

We used hierarchical regression to test our hypotheses. Model 1 of each hierarchical regression analysis is the posttest dependent variable regressed on the control variables (e.g., age, gender, marital status, and the covariate pretests for the dependent and independent variables). Model 2 is the posttest dependent variable regressed on the posttest independent variable. $\mathrm{R}^{2}$ for each regression equation is the amount of variance explained in the adjusted posttest dependent variable. Change in $R^{2}(\Delta R 2)$ between Model 1 and Model 2 is our measure of effect size, or the strength of association between the posttest independent and dependent variables when holding control and covariate variables constant.

There are multiple criteria to test for mediation of the relationship between an independent variable (peer support) and dependent variable (perceived PTSD symptoms) by mediator variables (SE and GSE) (Kenny, Kashy, \& Bolger, 1998). To demonstrate partial mediation, a) the independent variable and dependent variable must be significantly related, b) the mediator variable and dependent variable must be significantly related, and c) the independent variable and mediator variable must be significantly related. To demonstrate complete mediation, an additional criterion is that after controlling for the mediator, the independent variable has no significant effect on the dependent variable.

\section{RESULTS}

The mean, standard deviation, and sample size for each measure and their bivariate inter-correlations are reported in Table 1. Descriptive bivariate statistics show that there are significant $(\mathrm{p}<.001)$ and strong, positive pretest-posttest correlations for peer support $(\mathrm{r}=.73)$, GSE $(\mathrm{r}=.65)$, SE $(\mathrm{r}=.60)$, and perceived PTSD symptoms $(\mathrm{r}=.87)$. The paired $\mathrm{t}$-tests for each pretest-posttest mean difference are significant $(\mathrm{p}<.001)$ for peer support $(t=5.15)$, GSE $(t=5.31)$, SE $(t=7.18)$, and perceived PTSD symptoms $(t=-5.19)$. Higher pretest scores for peer support, general self-efficacy, and situation-specific selfefficacy predict higher scores on their respective posttests, whereas for perceived PTSD symptoms, a higher pretest score predicts a lower posttest score. These findings offer support that change occurred in these measures over the course of weekend retreats. 
Table 1. Means, Standard Deviations, Sample Sizes, and Pearson Inter-correlations

\begin{tabular}{|c|c|c|c|c|c|c|c|c|c|c|c|c|c|}
\hline Variable & Mean & SD & $\mathrm{N}$ & 1 & 2 & 3 & 4 & 5 & 6 & 7 & 8 & 9 & 10 \\
\hline \multicolumn{14}{|l|}{ Pretest (1) } \\
\hline 1. Support-1 & 3.6 & 1.4 & 211 & --- & & & & & & & & & \\
\hline 2. GES-1 & 3.1 & .6 & 211 & $.51^{* *}$ & --- & & & & & & & & \\
\hline 3. SE-1 & 4.1 & 1.2 & 208 & $.55^{* *}$ & $.52 * *$ & --- & & & & & & & \\
\hline 4. PTSD-1 & 3.0 & .8 & 182 & $-.60 * *$ & $-.53 * *$ & $-.68 * *$ & --- & & & & & & \\
\hline \multicolumn{14}{|l|}{ Posttest (2) } \\
\hline 5. Support-2 & 4.0 & 1.3 & 212 & $.73^{* *}$ & $.34^{* *}$ & $.41^{* *}$ & $-.48 * *$ & --- & & & & & \\
\hline 6. GES-2 & 3.2 & .5 & 211 & $.42^{* *}$ & $.65^{* *}$ & $.40^{* *}$ & $-.37 * *$ & $.51^{* *}$ & --- & & & & \\
\hline 7. $\mathrm{SE}-2$ & 4.7 & 1.0 & 185 & $.45^{* *}$ & $.54 * *$ & $.60^{* *}$ & $-.52 * *$ & $.56^{* *}$ & $.59 * *$ & --- & & & \\
\hline 8. PTSD-2 & 2.7 & .8 & 185 & $-.55 * *$ & $-.44 * *$ & $-.64 * *$ & $.87 * *$ & $-.51 * *$ & $-.38 * *$ & $-.56 * *$ & --- & & \\
\hline \multicolumn{14}{|l|}{ Background } \\
\hline 9. Age & 36.9 & 11.2 & 212 & .08 & .01 & .11 & .00 & .04 & -.03 & .06 & .02 & --- & \\
\hline 10. Gender ${ }^{a}$ & .3 & .5 & 212 & .04 & -.03 & -.04 & .03 & $.11^{*}$ & .06 & .08 & -.02 & $.12 *$ & --- \\
\hline 11. Married $^{\mathrm{b}}$ & .4 & .5 & 208 & $.21^{*}$ & $.12^{*}$ & $.21^{* *}$ & $-.12 *$ & $.16^{*}$ & .11 & $.19 * *$ & -.14 & $.27^{* *}$ & $-.25 * *$ \\
\hline
\end{tabular}


Table 2 shows the hierarchical regression analyses for evaluating the influence of peer support on perceived PTSD symptoms, SE, and GSE. Tables 3 and 4 show the hierarchical regression analyses for evaluating the influence of SE and GSE on PTSD symptoms. In Tables 2 through 4, Model 1 for each analysis regresses the dependent variable only on the control and covariate variables. Note that, unlike previous studies, the control variables of age, gender, and marital status are consistently insignificant in predicting PTSD symptoms, GSE, or SE. Model 2 for each analysis regresses the dependent variable on the independent variable in addition to the control and covariate variables.

Hypothesis 1 is that increased peer support reduces perceived PTSD symptoms. As shown in Table 2-Part $\mathrm{A}$, the amount of change in variance explained is very small but significant $\left(\Delta \mathrm{R}^{2}=.01, \mathrm{p}<.05\right)$ in comparing Model $1\left(\mathrm{R}_{1}{ }^{2}=.79\right)$ and Model $2\left(\mathrm{R}_{2}{ }^{2}=.80\right)$ where posttest peer support is added to the regression equation with the control and covariate variables. The standardized coefficient (Beta $=-.15, \mathrm{p}<.001$ ) shows that one standard deviation increase in posttest peer support is necessary to reduce posttest PTSD symptoms by only .15 standard deviations when holding control and covariate variables constant. These finding supports the hypothesis.

Hypothesis 2 is that increased situation-specific self-efficacy reduces perceived PTSD. As shown in Table 3, the amount of change in variance explained is very small but significant $\left(\Delta \mathrm{R}^{2}=.01, \mathrm{p}<.01\right)$ in comparing Model $1\left(\mathrm{R}_{1}{ }^{2}=.80\right)$ with Model $2\left(\mathrm{R}_{2}{ }^{2}=\right.$ .81) where $\mathrm{SE}$ is added to the regression equation with the control and covariate variables. The significant standardized coefficient (Beta $=-.14, \mathrm{p}<.01$ ) indicates that a one standard deviation increase in posttest GSE reduces perceived posttest PTSD symptoms by only .14 standard deviations when holding other control and covariate variables constant. These findings support the hypothesis.

Hypothesis 3 is that increased general self-efficacy reduces perceived PTSD symptoms. As shown in Table 4, the amount of change in variance explained is very small but significant $\left(\Delta \mathrm{R}^{2}=.01, \mathrm{p}<.01\right)$ in comparing Model $1\left(\mathrm{R}_{1}{ }^{2}=.78\right)$ with Model 2 $\left(\mathrm{R}_{2}{ }^{2}=.79\right)$ where GSE is added to the regression equation with the control and covariate variables. The significant standardized coefficient (Beta $=-.12, \mathrm{p}<.01$ ) indicates that a one standard deviation increase in posttest GSE reduces perceived posttest PTSD symptoms by only .12 standard deviations when holding other control and covariate variables constant. These findings support the hypothesis.

The last two hypotheses are that situation-specific self-efficacy (Hypothesis 4) and general self-efficacy (Hypothesis 5) will play a mediator role in explaining the relationship between peer support and perceived PTSD symptoms. Kenny, Kasher, \& Bolger (1998) defined the criteria for demonstrating mediation. The first criterion is the same as the supported Hypothesis 1, namely that the independent variable of posttest peer support reduces perceived PTDS symptoms. The second criterion is the same as the supported Hypothesis 2 and Hypothesis 3, namely that the mediator variable of SE and GSE respectively reduces perceived PTSD symptoms. The third criterion is that the relationship is significant between the independent variable of posttest peer support and the mediator variables of SE and GSE respectively. As shown in Table 2-Part B and Part 
Table 2. Hierarchical Regressions with Posttest Peer Support as the Independent Variable

\begin{tabular}{|c|c|c|c|c|c|c|c|c|c|c|}
\hline \multirow[b]{2}{*}{ Dependent Variable (DV) } & \multicolumn{6}{|c|}{ Betas } & \multicolumn{4}{|c|}{$\begin{array}{l}\mathrm{R}^{2} \text { for Model } 1 \text { and Model } 2 \text { with } \\
\text { change in } \mathrm{R}^{2} \text { from Model } 1 \text { to } 2\end{array}$} \\
\hline & $\begin{array}{l}\text { Pretest } \\
\text { DV }\end{array}$ & $\begin{array}{l}\text { Pretest } \\
\text { Support }\end{array}$ & Age & Gender & Married & $\begin{array}{l}\text { Posttest } \\
\text { Support }\end{array}$ & $\mathrm{R}_{1}^{2}$ & $\mathrm{R}_{2}^{2}$ & $\Delta \mathrm{R}^{2}$ & $\Delta \mathrm{F}$ \\
\hline \multicolumn{11}{|l|}{ A. Posttest PTSD } \\
\hline Model 1: Controls & $.86^{* * *}$ & -.03 & .01 & -.02 & -.07 & & $.79^{* * *}$ & & & 125.26 \\
\hline Model 2: Add posttest support & $.85^{* *}$ & .08 & .01 & .00 & -.05 & $-.15^{* *}$ & & $.80^{* * *}$ & $.01^{*}$ & 7.31 \\
\hline \multicolumn{11}{|l|}{ B. Posttest self-efficacy } \\
\hline Model 1: Controls & $.50^{* * *}$ & .14 & -.03 & .11 & .03 & & $.38^{* * *}$ & & & 19.19 \\
\hline Model 2: Add posttest support & $.51^{* * *}$ & $-.20 *$ & -.03 & .04 & .10 & $.47^{* * *}$ & & $.48^{* * *}$ & $.10^{* * *}$ & 31.94 \\
\hline \multicolumn{11}{|l|}{ C. Posttest general self-efficacy } \\
\hline Model 1: Controls & $.59 * * *$ & .12 & -.07 & .05 & .06 & & $.45^{* * *}$ & & & 32.36 \\
\hline Model 2: Add posttest support & $.61^{* * *}$ & $-.23 * *$ & -.05 & .00 & .04 & $.48^{* * *}$ & & $.55^{* * *}$ & $.10 * * *$ & 43.70 \\
\hline
\end{tabular}


Table 3. Hierarchical Regressions with Posttest "Situation-specific" Self-efficacy as the Independent Variable

\begin{tabular}{|c|c|c|c|c|c|c|c|c|c|c|}
\hline \multirow[b]{2}{*}{ Dependent Variable (DV) } & \multicolumn{6}{|c|}{ Betas } & \multicolumn{4}{|c|}{$\begin{array}{l}\mathrm{R}^{2} \text { for Model } 1 \text { and Model } 2 \text { with } \\
\text { change in } \mathrm{R}^{2} \text { from Model } 1 \text { to } 2\end{array}$} \\
\hline & $\begin{array}{l}\text { Pretest } \\
\text { DV }\end{array}$ & $\begin{array}{l}\text { Pretest } \\
\text { SE }\end{array}$ & Age & Gender & Married & $\begin{array}{l}\text { Posttest } \\
\text { SE }\end{array}$ & $\mathrm{R}_{1}^{2}$ & $\mathrm{R}_{2}^{2}$ & $\Delta \mathrm{R}^{2}$ & $\Delta \mathrm{F}$ \\
\hline \multicolumn{11}{|l|}{ Posttest PTSD } \\
\hline Model 1: Controls & $.73^{* * *}$ & $-.20 * * *$ & .04 & -.03 & -.04 & & $.80 * * *$ & & & 109.46 \\
\hline $\begin{array}{l}\text { Model 2: Add posttest self- } \\
\text { efficacy }\end{array}$ & $.72 * * *$ & $-.12 *$ & .04 & -.01 & -.03 & $-.14^{* *}$ & & $.81^{* * *}$ & $.01^{* *}$ & 7.45 \\
\hline
\end{tabular}

Table 4. Hierarchical Regressions with Posttest General Self-efficacy (GSE) as the Independent Variable

\begin{tabular}{|c|c|c|c|c|c|c|c|c|c|c|}
\hline \multirow[b]{2}{*}{ Dependent Variable (DV) } & \multicolumn{6}{|c|}{ Betas } & \multicolumn{4}{|c|}{$\begin{array}{l}\mathrm{R}^{2} \text { for Model } 1 \text { and Model } 2 \text { with } \\
\text { change in } \mathrm{R}^{2} \text { from Model } 1 \text { to } 2\end{array}$} \\
\hline & $\begin{array}{l}\text { Pretest } \\
\text { DV }\end{array}$ & $\begin{array}{l}\text { Pretest } \\
\text { GSE }\end{array}$ & Age & Gender & Married & $\begin{array}{l}\text { Posttest } \\
\text { GSE }\end{array}$ & $\mathrm{R}_{1}^{2}$ & $\mathrm{R}_{2}{ }^{2}$ & $\Delta \mathrm{R}^{2}$ & $\Delta \mathrm{F}$ \\
\hline \multicolumn{11}{|l|}{ Posttest PTSD } \\
\hline Model 1: Controls & $.86 * * *$ & -.03 & .01 & -.02 & -.07 & & $.78 * * *$ & & & 125.18 \\
\hline Model 2: Add posttest GSE & $.86 * * *$ & .05 & .01 & -.02 & -.06 & $-.12 * *$ & & $.79 * * *$ & $.01^{* *}$ & 5.56 \\
\hline
\end{tabular}


$\mathrm{C}$, this criterion is supported by the strong significant relationship of peer support to both SE $($ Beta $=.47, \mathrm{p}<.001)$ and GSE (Beta $=.48, \mathrm{p}<.001)$. A one standard deviation increase in posttest peer support increases SE or GSE respectively by .47 or .48 standard deviations when holding other control and covariate variables constant. A fourth criterion is necessary to demonstrate full mediation, namely that the relationship between posttest peer support and perceived PTSD symptoms must be reduced to insignificance when controlling for posttest SE or GSE respectively. This criterion is satisfied when controlling for the control variables for posttest SE (Beta $=-.07, \mathrm{p}>.05$ ) and posttest GSE (Beta $=-.12, p>.05$ ) respectively. The findings for all four criteria together support Hypotheses 4 and 5.

\section{DISCUSSION}

This study contributes to the limited empirical knowledge about the effectiveness of peer support for veterans who have returned to civilian life, especially in regards to OIF/OEF veterans (Ozer et al., 2003). Perceived increases in peer support foster a significant but small reduction of perceived PTSD symptoms, as do increases in situation-specific self-efficacy and general self-efficacy. From a conceptual perspective, as Benight and Bandura (2004) report, little is known about the role of self-efficacy as a mediator variable between combat-related trauma and peer support. The strong, significant relationship between peer support and self-efficacy here suggests that peer support as change-oriented process provides an enabling environment that promotes selfefficacy beliefs regarding proactive, adaptive coping with PTSD symptoms. This mediator role was played by both situation-specific self-efficacy and the more futureoriented, optimistic concept of general self-efficacy.

These findings must be balanced with a number of study limitations. Although all hypotheses are supported, the strength of relationship is small between reduced PTSD symptoms, peer support, and self-efficacy. This change in PTSD symptoms may have resulted for reasons other than increased peer support or self-efficacy. For example, it may be that an intense weekend retreat created a positive 'bounce' effect in selfevaluation that will shortly diminish. The literature does suggest, however, that the effect of peer support for veterans is cumulative over time (Ozer et al., 2003). Longitudinal, follow-up studies are needed to compare the initial and cumulative effects of different peer support formats. Another study limitation, perhaps best corrected by randomization to different groups when possible, is selection bias of participants in terms of attending a weekend retreat. Measurement could be improved by, for example, a) additional peer support measures to enhance understanding of the emotional, cognitive and social meanings of peer support, and b) increasing the range of outcomes to include more about the management of combat-related trauma and pain, social relationships, and instrumental needs such as use of veteran benefits, education, and employment to indicate how peer support is most helpful. 


\section{Implications for Social Work}

Recognizing the behavioral health needs of veterans is an essential first step in the design of services. The recognition needs to be followed with referral for appropriate services. Social workers need to advocate on behalf of veterans to ensure they receive the benefits they and their families are entitled to. This requires assessing support systems and resources. Encouraging agencies to develop peer support programs that are sensitive to the needs of veterans can be a proactive strategy. Peer support plays a role in wellbeing and is consistent with the bio-psycho-social model and client-centered practice. This model assumes the client possesses strengths such as self-efficacy and resources that can be used to ameliorate current challenges in the fit between person and environment. Veterans face serious challenges as they integrate into civilian life after exposure to the multiple traumas associated with combat. Reliance on peer support, a core component of military culture and camaraderie, can play a critical role in re-integration. Using the resources they had in civilian life as well as the acquired coping skills such as selfefficacy that they developed during their military service, they can now go about the seemingly daunting task of returning to civilian life. The behavioral health needs of the increasing number of returning veterans may strain services at the community level. Engagement in the political process can ensure that the funding for these services is available. In addition, there is growing empirical evidence that peer support may be an important "extra-therapeutic" factor in psychotherapy outcomes generally (Roehrle \& Strouse, 2008) and for veterans (Barber et al., 2008) including OIF/OEF veterans (Price et al., 2011). Augmenting professional services by using such cost-effective strategies as peer support groups that rely on the strengths of the veterans should be pursued.

From an ecological perspective, veterans are often not alone in coping with their PTSD symptoms. About $40 \%$ of participants in this study were married. As Sherman, Blevins, Kirchner, and Ridener (2008, p. 443) summarize, there are "often complicated, multi-layered family issues of people living with posttraumatic stress disorder." For married veterans or veterans with partners, Vets4Vets might expand the social support network by including a family focus through psycho-education and concurrent peer support for family members. This may facilitate recognizing the potential impact of untreated behavioral health problems on all family members and information about available resources. From a broader community perspective, social workers in schools or other family-oriented settings may see family members who are trying to deal with hyper-vigilance or the emotional numbness of veterans without being aware these are PTSD symptoms. Here information and referral for veteran benefits and services would further assist families of veterans with their struggles.

Lastly, the weekend retreat potentially has much to offer the social service community. Weekend retreats allow for an intensive amount of bonding time in a short time frame, which is often how veterans experience camaraderie. Moreover, as time pressures of family, work, and other responsibilities increase, the weekend can be the time most easily available for intervention. This may be especially true if spouses and partners are included in the intervention. From an agency perspective, use of weekend retreats may be a way to efficiently extend services to a wider clientele such as veterans. 


\section{References}

Bandura, A. (1994). Self-efficacy. In R. J. Corsini (Ed.), Encyclopedia of psychology (2 ${ }^{\text {nd }}$ ed., Vol. 3, pp. 368-369). New York: J. Wiley \& Sons.

Bandura, A. (1997). Self-efficacy. New York: W. H. Freeman and Company.

Barber, J. A., Rosenheck, R. A., Armstrong, M., \& Resnick, S. G. (2008). Monitoring the dissemination of peer support in the VA health care system. Community Mental Health Journal, 44, 433-441.

Benight, C. C., \& Bandura, A. (2004). Social cognitive theory of posttraumatic recovery: the role of perceived self-efficacy. Behavioral Research and Therapy, 42, 1129-1148.

Brewin, C. R., Andrews, B., \& Valentine, J. D. (2000). Meta-analysis of risk factors for posttraumatic stress disorder in trauma-exposed adults. Journal of Consulting and Clinical Psychology, 68, 748-766.

Brown, L. D., \& Lucksted, A. (2010). Theoretical foundations of mental health self-help. In L. D. Brown \& S. Wituk (Eds.), Mental health self-help: Consumer and family initiatives (pp. 19-38). New York: Springer.

Burnam, M. A., Tanielian, T., \& Jaycox, L. H. (2009). Mental health care for Iraq and Afghanistan war veterans. Health Affairs, 28, 771-782.

Calhoun, L. G., \& Tedeschi, R. G. (2006). The foundations of posttraumatic growth: An expanded framework. In L. G. Calhoun \& R. G. Tedeschi (Eds.), Handbook of posttraumatic growth (pp. 1-23). Mahwah, NJ: Erlbaum.

Campbell, J. (2005). The historical and philosophical development of peer-run support programs. In S. Clay, B. Schell, P. Corrigan, \& R. Ralph (Eds.), On our own, together: Peer programs for people with mental illness (pp.17-66). Nashville, TN: Vanderbilt University Press.

Carter-Visscher, R., Polusny, M., Murdoch, M., Thuras, P., Erbes, C., \& Kehle, S. (2010). Pre-deployment gender differences in stressors and mental health among U.S. National Guard troops poised for Operation Iraqi Freedom deployment. Journal of Traumatic Stress Disorder, 23(1), 78-85.

Center for a New American Security. (2011). Losing the battle: The challenge of military suicide. Washington, DC: Center for a New American Security. Retrieved from http://www.cnas.org/files/documents/publications/CNAS_LosingTheBattle_HarrellB erglass.pdf

Clay, S. (2005). About us: What we have in common. In S. Clay, B. Schell, P. Corrigan, \& R. Ralph (Eds.), On our own, together: Peer programs for people with mental illness (pp. 3-16). Nashville, TN: Vanderbilt University Press.

Connor, K., \& Davidson, J. (2001). SPRINT: A brief global assessment of post-traumatic stress disorder. International Clinical Psychopharmacology, 16, 279-284. 
Davidson, J., \& Colket, J. (1997). The eight-item treatment outcome post-traumatic stress disorder scale: A brief measure to assess treatment outcome in post-traumatic stress disorder. International Clinical Psychopharmacology, 12, 41-45

Davidson, L., Chinman, M., Kloos, B., Weingarten, R., Stayner, D., \& Tebes, J. K. 1999). Peer support among individuals with severe mental illness: A review of the evidence. Clinical Psychology: Science and Practice, 6(2), 165-187.

Dimitrov, D. M., \& Rumrill, P. D. Jr. (2003). Pretest-posttest designs and measurement of change. Work, 20, 159-165.

Eibner, C. (2008). Invisible Wounds of War: Quantifying the Societal Costs of Psychological and Cognitive Injuries. Santa Monica, CA: RAND Corporation. Retrieved from http://www.rand.org/pubs/testimonies/CT309/

Goldstrom, I. D., Campbell, J., Rogers, J. A., Lambert, D. B., Blacklow, B., Henderson, M. J., \& Manderscheid, R. (2006). National estimates for mental health mutual support groups, self-help organization, and consumer-operated services. Administration and Policy in Mental Health and Mental Health Services Research, 33, 92-103.

Helgeson, V. S., \& Gottlieb, B. H. (2000). Support groups. In S. Cohen, L.G. Underwood, \& B. H. Gottlieb (Eds.), Social Support measurement and intervention: A guide for health and social scientists (pp. 221-245). Oxford: Oxford University Press.

Hirschhorn, L., \& Gilmore, T. N. (2004). Working in retreats: Learning from the group relations tradition. In L. J. Gould, L. F. Stapley, \& M. Stein (Eds.), Experiential learning in organizations: Applications of the Tavistock Group Relations Approach (pp. 85-100). London: Karnac Books.

Institute of Medicine. (2010). Returning home from Iraq and Afghanistan: Preliminary assessment of readjustment needs of veterans, service members, and their families. Washington, DC: The National Academies Press. Retrieved from http://www.nap.edu/catalog/12812.html.

Kenny, D. A., Kashy, D. A., \& Bolger, N. (1998). Data analysis in social psychology. In D. T. Gilber, S. T. Fiske, \& G. Lindzey (Eds.), The handbook of social psychology (Vol. 1, pp. 223-265). Boston, MA: McGraw-Hill.

Kohut., H. (1984). How does analysis cure? New York: International Universities Press.

Kurtz, L. F. (1997). Self-help and support groups: A handbook for practitioners. Thousand Oaks, CA: Sage.

Lee, R. M., Draper, M., \& Lee, S. (2001). Social connectedness, dysfunctional interpersonal behaviors, and psychological distress: Testing a mediator model. Journal of Consulting Psychology, 48(3), 310-318.

Lee, R. M., \& Robbins, S. B. (1995). Measuring belongingness: The social connectedness and the social assurance scales. Journal of Counseling Psychology, 42(2), 232-241. 
Liteman, M., Campbell, S., \& Liteman, J. (2006). Retreats that work: Everything you need to know about planning and leading great offsites (Expanded ed.). San Francisco: Pfeiffer.

Martone, K. (2010). Retreats for personal growth. In S. Walfish (Ed.), Earning a living outside of managed mental health care: 50 ways to expand your practice (pp. 219221). Washington, DC: American Psychological Association.

Mead, S., Hilton, D., \& Curtis, L. (2001). Peer support: A theoretical perspective. Psychiatric Rehabilitation Journal, 25, 134-141.

NBC Nightly News Weekend Edition. (2009, June 2). Retrieved from http://www.youtube.com/watch?v=bo3y0Oa8fog

Orloff, S. F., Armstrong, D., \& Remke, S. S. (2009). Adolescent encounters with death, bereavement, and coping. New York: Springer.

Ozer, E. J., Best, S. R., Lipsey, T. L., \& Weiss, D. S. (2003). Predictors of posttraumatic stress disorder and symptoms in adults: A meta-analysis. Psychological Bulletin, 129, 52-74.

Pietrzak, R. H., Goldstein, M. B., Malley, J. C., Rivers, A. J., \& Southwick, S. M. (2010). Structure of posttraumatic stress disorder symptoms and psychosocial functioning in Veterans of Operations Enduring Freedom and Iraqi Freedom. Psychiatry Research, 178, 323-329.

Poole, R. M. (2010, September). Pathway House. Smithsonian, 68-71.

Price, M., Gros, D. F., Strachan, M., Ruggiero, K. J., \& Acierno, R. (2011, November 7). The role of social support in exposure therapy for Operation Iraqi Freedom/Operation Enduring Freedom Veterans: A preliminary investigation. Psychological Trauma: Theory, Research, Practice, and Policy, 1-8. doi: 10.1037/a0026244

Rains, S. A., \& Young, V. (2009). A meta-analysis of research on formal computermediated support groups: Examining group characteristics and health outcomes. Human Communication Research, 35(3), 309-336.

Resnick, S. G., \& Rosenheck, R. A. (2008). Integrating peer-provided services: A quasiexperimental study of recovery orientation, confidence, and empowerment. Psychiatric Services, 59(11), 1307-1314.

Roehrle, B., \& Strouse, J. (2008). Influence of social support on success of therapeutic interventions: A meta-analytic review. Psychotherapy Theory, Research, Practice, Training, 45(4), 464-476.

Rubin, A., \& Babbie, E. R. (2010). Research methods for social work ( $7^{\text {th }}$ ed.). New York: Brooks Cole.

Saleebey, D. (2006). The strengths perspective in social work practice $\left(4^{\text {th }} \mathrm{ed}\right.$.). Boston: Allyn \& Bacon. 
Schell, T. L., \& Tanielian, T. (Eds.). (2011). A needs assessment of New York State veterans. Santa Monica, CA: RAND Corporation. Retrieved from http://www.rand.org/pubs/technical reports/TR920.html

Schwarzer, R. (Ed.). (1992). Self-efficacy: Thought control of action. Washington, DC: Hemisphere.

Schwarzer, R., \& Fuchs, R. (1996). Self-efficacy and health behaviors. In M. Conner \& P. Norman (Eds.). Predicting health behavior: Research and practice with social cognition models (pp. 163-196). Buckingham, UK: Open University Press.

Schwarzer, R., \& Jerusalem, M. (1995). Generalized Self-Efficacy scale. In J. Weinman, S. Wright, \& M. Johnston (Eds.), Measures in health psychology: A user's portfolio. Causal and control beliefs (pp. 35-37). Windsor, England: NFER-NELSON.

Seligman, M. E. P. (2011). Flourish: A visionary new understanding of happiness and well-being. New York: Free Press.

Sherman, M. D., Blevins, D., Kirchner, J., \& Ridener, L. (2008). Key factors involved in engaging significant others in the treatment of Vietnam veterans with PTSD. Professional Psychology: Research and Practice, 39(4), 443-450.

Solomon, P. (2004). Peer support/peer provided services underlying processes, benefits, and critical ingredients. Psychiatric Rehabilitation Journal, 27(4), 392-401.

Tanielian, T., \& Jaycox, L. (2008). Invisible wounds of war: Psychological and cognitive injuries, their consequences, and services to assist recovery. Santa Monica, CA: RAND Corporation. Retrieved from http://www.rand.org/pubs/monographs/MG720.html.

Vernon, L. L., Dillon, J. M., \& Steiner, A. R. W. (2009). Proactive coping, gratitude, and posttraumatic stress disorder in college women. Anxiety, Stress \& Coping, 22(1), 117-127.

Vets4Vets. (2011). About Vets4Vets. Vets4Vets website. Retrieved from http://www.vets4vets.us.

Worthen, M. (2011). The relations between traumatic exposures, Posttraumatic Stress Disorder, and anger in male and female veterans. Journal of Feminist Family Therapy, 23, 188-201.

\section{Author note:}

Address correspondence to: Nora Gustavsson, Arizona State University, College of Public Programs, School of Social Work, 411 N. Central Ave, Suite 800, Phoenix, AZ 85004. Email: nora.gustavsson@asu.edu 